\title{
Effects of feeding garlic powder on growth performance and meat quality of broiler
}

\author{
Ali MS, M Kamruzzaman*, ZH Khandaker
}

Department of Animal Nutrition, Bangladesh Agricultural University, Mymensingh-2202, Bangladesh

\begin{abstract}
An experiment was conducted with 60 day old Cobb-500 broiler chicks for a period of 28 days with the aims of investigating the effects of different level of garlic powder on growth performance, carcass characteristics and meat quality of broilers to produce safe broiler meat. The experimental broiler chicks were divided randomly into four different groups with three replications having 5 chicks in each. Maizesoybean based diet was used as basal diet for group 1 . Basal diet was supplemented with $1 \%, 2 \%$ and $3 \%$ garlic powder on fresh basis for group 2,3 , and 4 respectively. The broiler of groups 2,3 , and 4 were showed significantly $(p>0.05)$ higher body weight than control group at 4 weeks of age. Feed conversion ratio of group 2,3 , and 4 were significantly $(p>0.05)$ lower than group 1 . Group 2 was given significantly lower fat percentage than other groups. Group 3 and 4 showed more or less similar fat content but lower than control groups. Thus, it may be concluded that garlic powder may be used in chicken diet.
\end{abstract}

Key words: broiler, garlic powder, growth, meat quality

Bangladesh Animal Husbandry Association. All rights reserved.

Bang. J. Anim. Sci. 2016. 45 (2): 79-83

\section{Introduction}

Garlic has been one of the medicinal plants of interest throughout human history as a medicinal panacea in almost every known culture (Rivlin et al., 2001). Since its discovery, the health beneficial activity of garlic has been partly attributed to its organosulfer compounds (Amagase et al., 2001). The major sulphercontaining compounds in intact garlic are alliin, diallylsulfieds and allicin (Amagase et al., 2001). Furthermore, a variety of components, including nonsulfur compounds such as saponins, work synergistically to exhibit various health benefits of garlic. Garlic is as a spice and herbal medicine for prevention and treatment of a variety of diseases (Adibmoradi et al., 2006). Garlic has been found to lower serum and tissue cholesterol levels (Stanacev et al., 2012), inhibit bacterial growth (Cavallito et al., 1994), inhibit platelet growth and reduce oxidative stress. In broilers, it was reported that garlic, as a natural feed additive, improved broiler growth and feed conversion ratio, and decreased mortality rate (Puvaca et al., 2014). Improvement of broilers performance, blood lipid profile and tissues can be achieved by supplementation of diets with garlic powder (Stanacev et al., 2011).

*Corresponding author: sajal_anbau@yahoo.com
It was reported that feeding garlic powder at levels of $1.5,3$ and $4.5 \%$ had no effect on poultry performance (Konjufca et al., 1997), but caused a significant reduction in poultry serum and liver cholesterol. Tissues cholesterol levels were decreased with feeding garlic powder to broiler chickens (Stanacev et al., 2012) which showed that addition of garlic to broilers diet has effects on chicken performance and lipid profile. In research of Puvaca et al., (2014), addition of various spice herbs and their mixture such as garlic, black pepper and hot red pepper led to an improved performance results and reduced mortality rate of chicken fed with addition of these spice herbs. Using garlic powder in broilers diet in research of Horton et al. (1991) had no significant effect on performance but had positive influence on meat quality and carcass yield. In Bangladesh, very few researches have been conducted and very little information is available about feeding garlic components on growth performance, and carcass characteristics in chicken. Thus, the present study was performed to investigate the feeding effects of garlic on growth performances and meat quality of broiler. 


\section{Materials and Methods}

\section{Experimental design and layout}

An experiment was conducted with day old broiler chicks for a period of 28 days from $9^{\text {th }}$ August to $6^{\text {th }}$ September, 2015. A total number of 60 Cobb 500 commercial broiler chicks were equally and randomly divided into four dietary treatment groups and each group was replicated to three sub groups and each replicate having 5 birds. There were four dietary treatments containing $0 \%, 1 \%, 2 \%$ and $3 \%$ garlic powder respectively.

\section{Collection of feed ingredients and preparation of ration}

Feed ingredients used in the experiment were purchased from Janani and Shah Paran feed shop of Mymensingh town. At first, maize, wheat and oyster shell were grinded individually with the help of a grinding machine. After weighing, a required amount of ground maize, wheat, soybean meal, rice polish and fish meal were mixed thoroughly. Soybean oil was mixed with this mixture. Then the required amount of dicalcium phosphate, vitamin mineral premix, DLmethionine, choline chloride, oyster shell, common salt were mixed thoroughly.

\section{Feeding management}

Mash feed was supplied to the birds two times (7.30am and 4.30pm) per day on ad libitum basis. For first 3 days, feeds were given on newspaper and then, round plastic feeders were used up to the end. Fresh clean drinking water was also supplied two times every day. Feeders were cleaned in each week and waterers were washed each time during supplying of water.

\section{Data collection and record keeping}

The amount of feed consumed by the experimental broilers of different treatment groups were calculated for every week by deducting the amount retained from the amount supplied in that week. The chicks were weighed at the time after arrival and then every 7 days intervals until the termination of the experiment at 28 days of age group wise. The weight was taken at the morning before feeding time. The average live weight and the weight gains of the broilers on different dietary treatments were calculated on weekly and at the end of the experiment. Feed conversion ratio was calculated as the unit of feed consumed per unit of body weight gain.

\section{Carcass characteristics}

At the end of the experiment, representative birds from each treatment were selected, weighed and sacrificed to determine carcass traits. Data such as live weight, blood weight, dressed weight, kidney weight, liver weight, heart weight, intestine weight, head weight, gizzard weight, shank weight, wing weight, spleen weight etc. were recorded treatment wise and converted into percentages of respective live weights prior to statistical analysis.

Table 1. Effects of garlic powder on growth performance and feed intake of broiler

\begin{tabular}{llllll}
\hline & \multicolumn{5}{c}{ Dietary treatments } \\
Parameters & $\mathrm{T}_{0}$ & $\mathrm{~T}_{1}$ & $\mathrm{~T}_{2}$ & $\mathrm{~T}_{3}$ & Level of significance \\
\hline Initial body weight $(\mathrm{g})$ & 50.53 & 55.67 & 55.73 & 53.53 & Non significant \\
Final body weight $(\mathrm{g}$ & $1230^{\mathrm{d}}$ & $1447^{\mathrm{b}}$ & $1403^{\mathrm{c}}$ & $1472^{\mathrm{a}}$ & ${ }^{*}$ \\
Total body weight gain $(\mathrm{g})$ & $1179^{\mathrm{d}}$ & $1391^{\mathrm{b}}$ & $1347^{\mathrm{c}}$ & $1418^{\mathrm{a}}$ & $*$ \\
Daily live weight gain $(\mathrm{g} / \mathrm{d})$ & $42.12^{\mathrm{c}}$ & $49.69^{\mathrm{ab}}$ & $48.12^{\mathrm{b}}$ & $50.66^{\mathrm{a}}$ & $*$ \\
DM intake & & & & & \\
Total dry matter intake $(\mathrm{g})$ & 2020.49 & 2146.14 & 2202.65 & 2134.68 & Non significant \\
Average dry matter intake(g/day) & 72.16 & 76.66 & 78.67 & 76.24 & Non significant \\
Total CP intake $(\mathrm{g})$ & 584.93 & 536.54 & 550.66 & 533.67 & Non significant \\
CP intake (g/day) & 20.89 & 19.16 & 19.67 & 19.06 & Non significant \\
FCR & $1.71^{\mathrm{a}}$ & $1.54^{\mathrm{c}}$ & $1.63^{\mathrm{b}}$ & $1.5^{\mathrm{d}}$ & * \\
\hline
\end{tabular}

Group 1, concentrate mixture with $0 \%$ garlic powder; Group 2, concentrate mixture with $1 \%$ garlic powder; Group 3, concentrate mixture with $2 \%$ garlic powder; Group 4 , concentrate mixture with $3 \%$ garlic powder. Different symbols mean ${ }^{*}$, significant at $5 \%$ level of significance, Superscripts a, b, c, and d mean values with dissimilar superscripts within same rows are significantly different. 


\section{Chemical analysis of feed}

Feed sample were analyzed following the method of AOAC (2004).

\section{Statistical analysis}

All recorded and calculated variable were subjected to analysis of variance (ANOVA) in a Completely Randomized Design (CRD) by following a statistical package using SPSS statistical computer package program. Duncan's Multiple Range Test (DMRT) was used to compare treatment means (Steel and Torrie, 1980).

\section{Results and Discussion}

\section{Effect of garlic powder on growth performance}

The effect of different levels of garlic powder with concentrated mixture on growth performance of broiler is shown in Table 1. The daily body weight gain was $42.12,49.69,48.12$ and $50.66 \mathrm{~g}$ respectively among the treatment groups. The highest live weight gain per day was obtained at treatment containing 3\% garlic powder. The daily live weight gain of broilers was significantly different among the groups. The results of this study indicated that, an addition of garlic powder at $3 \%$ level with concentrated mixture had beneficial effect on growth performance of broiler. This might be due to increased amounts of protein available at the cellular level for deposition in the body tissues. This result agrees with reports of Ortsergu et al., (2008) and Ademola et al., (2005), who reported an increased weight gain of rabbits and broilers, fed 1.5 and $2 \%$ garlic supplemented diets respectively. Pourali et al. (2010), showed that allicin in garlic promotes the performance of the intestinal flora thereby improving digestion and enhancing the utilization of energy, leading to improved growth.

The average total dry matter (DM) intake was 2020.49, 2146.14, 2202.65 and $2134.68 \mathrm{~g}$ for treatment $1,2,3$ and 4 respectively (Table 1 ). The dietary treatments did not differ significantly $(P>0.05)$ among the dietary groups. The average total crude protein (CP) intake of different dietary treatment was $584.93 \mathrm{~g}, 536.54 \mathrm{~g}, 550.66 \mathrm{~g}$ and $533.67 \mathrm{~g}$ for diet $1,2,3$ and 4 respectively (Table $1)$. There was no significant difference among the treatment groups. The average FCR on diet 1,2 ,
3 and 4 were $1.71,1.54,1.63$, and 1.50 respectively (Table 1 ) and it was expressed that adding of garlic powder increased feed efficiency in diet. This result agrees with the result of ElSayiad et al., (2003) on broiler who reported that the best results of feed conversion were recorded with $1 \%$ garlic. They observed that the improvement in feed conversion by garlic may be due to better efficiency of feed utilization, reducing animal pain and improve organs function. Javendel et al., (2008) who also fed herbal plants (ginger and garlic) as growth promoters in broiler diets and observed a pronounced improvement in their body weight gain and feed conversion ratio.

Table 2. Effects of garlic powder on meat quality of broiler

\begin{tabular}{|c|c|c|c|c|c|}
\hline \multirow[t]{2}{*}{ Parameters } & \multicolumn{4}{|c|}{ Dietary treatments } & \multirow{2}{*}{$\begin{array}{l}\text { Signi } \\
\text { fican } \\
\text { ce }\end{array}$} \\
\hline & $\mathrm{T}_{0}$ & $\mathrm{~T}_{1}$ & $\mathrm{~T}_{2}$ & $\mathrm{~T}_{3}$ & \\
\hline Carcass weight (g) & $780^{d}$ & $1020^{a}$ & $897^{b}$ & $834^{c}$ & * \\
\hline Dressing yield (\%) & 60.00 & 60.72 & 60.61 & 60.57 & NS \\
\hline $\mathrm{CP}(\%)$ & $17.65^{b}$ & $17.90^{\mathrm{b}}$ & $20.21^{a}$ & $20.19 a$ & * \\
\hline $\mathrm{EE}(\%)$ & $0.78^{a}$ & $0.51^{\mathrm{b}}$ & $0.72^{\mathrm{a}}$ & $0.75^{\mathrm{a}}$ & * \\
\hline
\end{tabular}

Group 1, concentrate mixture with $0 \%$ garlic powder; Group 2 , concentrate mixture with $1 \%$ garlic powder; Group 3, concentrate mixture with $2 \%$ garlic powder; Group 4, concentrate mixture with $3 \%$ garlic powder. Different symbols mean *, significant at $5 \%$ level of significance, Superscripts a, b, c, and d mean values with dissimilar superscripts are significantly different.

\section{Effect of garlic powder on meat quality of broiler}

The carcass weight was $780 \mathrm{~g}, 1020 \mathrm{~g}, 897 \mathrm{~g}$ and $834 \mathrm{~g}$ for dietary treatment $1,2,3$ and 4 respectively, which corresponded to $60.00 \%$, $60.72 \%, 60.61$ and $60.57 \%$ dressing yield (\%) respectively (Table 2 ). There was no significant difference among the groups in terms of dressing percentage, but carcass weight was significantly higher in garlic supplemented groups than control groups.

The crude protein (CP) content of meat was $17.65 \%, 17.90 \%, 20.21 \%$ and $20.19 \%$ for dietary treatment $1,2,3$ and 4 respectively and there was significant difference among the treatment groups. The results state that if garlic powder is supplemented with concentrated diets, crude protein (CP) percentage of meat will be increased. This result agrees the result of Shehata et al., (2003) who reported that addition of garlic with different levels improved DCP and 
TDN significantly. These results might be due to restore of important protein which increase glutathione enzymes in the liver which protects the cells from oxidative damage and play vital role in detoxification, inhibit lipid per oxidation, improve organs function and immunity. The ether extract (EE) was $0.78,0.51,0.72$ and $0.75 \%$ for dietary treatments $1,2,3$ and 4 respectively and it was found that garlic powder significantly decreased the fat content of meat. The result agrees with the reports of Fuhrman et al. (2000), reported that plant component had cholesterolsuppressive capacity.

The hypocholesterolemic effects of ginger and garlic reduced fat content in broiler meat for safe human consumption. Vidica et al. (2011), also reported that incorporation of $0.75 \%$ garlic in the diet of broilers reduced drastically the level of cholesterol in the meat. Chowdhury et al., (2002), showed that garlic has cholesterol lowering effect in layer chicken only due to the presence of sulphur containing bioactive compounds in its homogenates. Lydia (2001), also suggested that garlic supplementation could reduce fat deposition than control diet. The findings of Dieumou et al. (2009) and Fadlalla et al. (2010), in the diet of broilers reported a non- significant effect on broiler dressing percentage values (but numerically higher) due to the inclusion of garlic powder. The present result agrees with Lydia et al., (2001) who reported that there were no significant differences on carcass percentage of birds fed varying levels of garlic powder.

\section{Cost analysis of different treatments}

The costs of these four dietary treatments were $40.13,41.47,42.72$ and $44.03 \mathrm{Tk} / \mathrm{kg}$ for diet 1 , 2,3 and 4 respectively (Table 3 ). The results showed that there was no significantly difference for the price of diets among the treatments. The cost of production of the present research work is shown in the Table 3. The highest total production cost per $\mathrm{kg}$ broiler was obtained in group 1 and lowest in group 2.

\section{Conclusion}

It may be concluded that, supplementation of garlic improve growth performance, feed conversion efficiency and dressing yield of broilers. It also helps to reduce ether extract (EE) or fat content of broiler meat. So, it is recommended that garlic powder is used as supplement in modern poultry production and further research is necessary in this context.

Table 3. Cost analysis of broiler production under different dietary treatments

\begin{tabular}{llllll}
\hline \multirow{2}{*}{ Parameters } & \multicolumn{4}{c}{ Dietary treatments } & Level of significance \\
\cline { 2 - 5 } & $\mathrm{T}_{0}$ & $\mathrm{~T}_{1}$ & $\mathrm{~T}_{2}$ & $\mathrm{~T}_{3}$ & \\
\hline Cost/kg feed (Tk) & 40.13 & 41.47 & 42.72 & 44.03 & Non significant \\
Chick Price /bird (Tk) & 35.00 & 35.00 & 35.00 & 35.00 & Non significant \\
Feed intake kg/bird & 2.34 & 2.49 & 2.55 & 2.50 & Non significant \\
Total feed cost/broiler (Tk) & 93.93 & 103.34 & 109.08 & 110.27 & Non significant \\
Total cost (feed+chick) (Tk) & 128.93 & 138.34 & 144.08 & 145.27 & Non significant \\
Other cost/ broiler (Tk) & 20.00 & 20.00 & 20.00 & 20.00 & Non significant \\
Total production cost/broiler (Tk) & 148.93 & 158.34 & 164.08 & 165.27 & Non significant \\
Total production cost/ kg broiler (Tk) & $121.06^{\mathrm{a}}$ & $109.37^{\mathrm{c}}$ & $116.85^{\mathrm{b}}$ & $111.25^{\mathrm{c}}$ & Significant \\
Price ( @ 125 Tk)/broiler & 153.75 & 180.88 & 175.38 & 184.00 & Non significant \\
Profit (Tk)/broiler & 4.82 & 22.53 & 11.29 & 18.73 & Non significant \\
\hline
\end{tabular}

Group 1, concentrate mixture with $0 \%$ garlic powder; Group 2, concentrate mixture with $1 \%$ garlic powder; Group 3, concentrate mixture with $2 \%$ garlic powder; Group 4 , concentrate mixture with $3 \%$ garlic powder. Different symbols mean *, significant at $5 \%$ level of significance, Superscripts a, b, c, and d mean values with dissimilar superscripts within same rows are significantly different. 


\section{References}

Ademola, S. G., Farinu, G. O., Adelowo, O. O., Fadade, M. O., Babatunde, G. M. (2005). Growth performance antimicrobial activity of garlic and ginger mixture fed to broiler. Proceedings of the Nigerian Society for Animal Production, 71-74.

Adibmoradi, M., Navidshad, B., Seifdavati, J. and Royan, M. (2006).Effect of dietary garlic mealon histological structure of small intestine in broiler chickens. Journal of Poultry Science, 43:378383.

Amagase, H., Petesch, B. L., Matsuura, H., Kasuga, S., Itajura, Y. (2001). Intake of garlic and its bioactive components. Journal of Nutrition, 45:102-109.

Cavallito, C. J., Buck, J. S., Suter, C. M. (1994): Allicin, the antibacterialprinciple of Allium sativum. Determination of the chemical composition. Journal of American Chemical Society, 60: 1952-1958.

Chowdhury, S. R., Chowdhury, S. D., Smith, T. K. (2002). Effects of Dietary Garlic on Cholesterol Metabolism in Laying Hens. Journal of Poultry Science, 81:1856-1862

Dieumou F. E. A., Teguia J. R., Kuiate J. D., Tamokou N. B., Fonge A., Dongmo M. C. (2009). Effects of ginger and garlic essential oils on growth performance and gut microbial population of broiler chickens. Livestock Research for Rural Development, 21 (8).

El-sayiad G. A., Abdeen A. M., Abde, Latif K. M. (2003). Effect of parity, methionine, vitamin $E$ and vitamin $C$ on rabbit performance during the hot year months in Egyptian Journal of Agriculture Research, 3 (2): 485-505

Fadlalla, I. M. T., Mohammed B. H., Bakhiet A. O. (2010). Effect of feeding garlic on the performance and immunity of broilers. Asian Journal of Poultry Science, 4: 182-189.

Furhman B, Rosenblat M, Hayek T, Coleman R, Aviram M (2000). Ginger extract consumption reduces plasma cholesterol and attenuates development of atherosclerosis in atherosclerotic, polipoprotein E-deficient mice. Journal of Nutrition, 130:1124-1131.

Horton, G. M. J., Fennell, M. J., Prasad, B. M. (1991). Effects of dietary garlic on performance, carcass composition and blood chemistry changes in broiler chickens. Canadian Journal of Animal Science, 71: 939-942.

Javandel, F. B., Navidshad, J., Seifdavati, G. H., Pourrahimi, and S. Baniyaghoub. (2008). The favorite dosage of garlic meal as a feed additive in broiler chickens ratios. Pakistan Journal of Biological Science, 11(13): $1746-1749$.

Konjufca, V. H., Pesti, G. M., Bakalli, R. I. (1997). Modulation of cholesterol levels in broiler meat by dietary garlic and copper. Journal of Poultry Science, 76:1264-1271.

Konjufca, V. H., Pesti, G. M. and Bakalli, R. I. (1997). Modulation of cholesterol levels in broiler meat by dietary garlic and Copper. Journal of Poultry Science, 76: 1264-1271.

Lydia, D. (2001). Advances in Therapy. July-August, 2001, 8: 189-193.

Ortserga D. D., Andyar A. C., Anthony T. I. (2008). Growth performance of growing rabbits fed graded levels of garlic. Proceedings of the $33^{\text {rd }}$ Annual Conference of the Nigerian Society for Animal Production, 189-191.

Pourali M., Mirghelenj S. A., Kermanshashi D. (2010). Effect of garlic powder on productive performance and immune response of broiler chickens challenged with Newcastle disease virus. Global Veterinarian, 4:616-621.

Puvaca, N., Lukac, D., Stanacev, V., Kostadinovic, Lj.,Beuković, M., Ljubojevic, D., Zec, S. (2014). Effect of spice herbs inbroiler chicken nutrition on productive performances. Procedings of $15^{\text {th }}$ International symposium Feed Technology, 2830

Rivlin, R. S. (2001). Historical perspective on the use of garlic Journal of Nutrition, 131 (35): 957954

Shehata, S. A., Askar A. A., Mohamed M. S. (2003). Reducing of the dietary toxicity of T-2 toxin and diacetoxyscripenol (DAS) by garlic in fish.Journal of Agricultural Science. Mansoura University, 28 (10): 7169-7182.

Stanacev, V., Glamocic, D., Milosevic, N., Peric, L., Puvaca, N., Stanacev, V., Milic, D., Plavsa, N. (2012).Influence of garlic and copper as phyto additives in the feed on the content of cholesterol in the tissues of the chickens. Journal of Medicinal Plants Research, 6: 28162819.

Stanacev, V., Glamocic, D., Milosevic, N., Puvaca, N., Stanacev, V., Plavsa, N. (2011).Effect of garlic in fattening chick's nutrition. African Journal of Agricultural Research, 6: 943-948.

Steel, R. D. G. and Torrie, J. H. (1980).A study of the need for fibre by growing New Zealand White rabbit. Journal of Science of Food and Agriculture, 29:640-648. 